\title{
DELIBERATIVE DEMOCRACY
}

Jürg Steiner

Original Scientific Paper

University of North Carolina at Chapel Hill and UDK 316.454.5:141.7

University of Bern

Maria Clara Jaramillo

University of Cali, Colombia

Simona Mameli

University of Bern

\section{THE DYNAMICS OF DELIBERATION}

Abstract: Existing instruments to measure the quality of deliberation are too static, focusing too much on the analysis of the individual speech acts. We present an instrument to identify Deliberative Transformative Moments (DTM) lifting the level of deliberation from a low to high or vice versa. To use this instrument, one has to look at the group dynamics of the entire discussion. Empirical basis are discussions among Colombian ex-combatants from both the extreme left and the extreme right. We investigate to what extent personal stories have either a positive or a negative impact on deliberative transformative moments. A corresponding typology of personal stories is developed.

This paper is a continuation of previous research on the deliberative model of democracy. ${ }^{1}$ Good scholarship should ideally be creative destruction of one's previous research. ${ }^{2}$ This is precisely what we want to do in our current research, although not in an extreme form. In our previous research, we developed the method of Discourse Quality Index (DQI) to measure the deliberative quality of the speech acts of discussions in parliaments and also among ordinary citizens. The values for the individual speech acts were aggregated for the individual participants and also for the discussion groups at large. Theoretically,

1 Jürg Steiner, André Bächtiger, Markus Spörndli, and Marco R. Steenbergen, Deliberative Politics in Action. Analysing Parliamentary Discourse, Cambridge University Press, 2005. Jürg Steiner, The Foundations of Deliberative Democracy. Empirical Research and Normative Implications, Cambridge University Press, 2012.

2 Analogous to what Joseph Schumpeter postulated for the economy; Joseph Schumpeter, Capitalism, Socialism and Democracy, third edition, New York: Harper and Row, 1950. 
we could explain variation in these aggregated values in their antecedents and consequences. The measurement instrument of the DQI has now been widely used all over the world. ${ }^{3}$ We consider it still as useful instrument for many purposes, but acknowledge that it is too static to get at the dynamics of group discussions. We have now created the concept of Deliberative Transformative Moment (DTM) to identify situations when the group dynamics lead to an upswing or a downswing in the level of deliberative quality. The purpose of this paper is to introduce this new concept into the deliberative literature.

As academics, we know intuitively from our everyday experience of sitting in all kind of meetings that all of a sudden the tone of a meeting may change, getting either more deliberative or less so. Thus, at the intuitive level, we are familiar with the concept of deliberative transformative moments. In this paper, we attempt to get more systematically at such situations. On the one hand, we try to identify situations where the discussion drags on at a low level of deliberation, and then something occurs to transform it to a high level. On the other hand, we investigate situations where the discussion flows at a high level of deliberation, and then something occurs to transform it to a low level. Our basic theoretical question is what this something can be. First, we want to show why the DQI is not sufficient to get at these dynamics. ${ }^{4}$ Then, we will show how we identify Deliberative Transformative Moments (DTM).

The DQI measures the various deliberative dimensions. The units of analysis are the individual speech acts. Each speech act is coded according to given categories for each dimension. One dimension is how well arguments are justified. The coding categories refer to how well reasons and conclusions are linked. Personal stories also count as good justifications as long as they are linked to the issue under discussion. A second dimension refers to the respect that is paid to other actors and the arguments they present. A third dimension asks to what extent arguments are justified in terms of the public good. Self-interest are compatible with good deliberation, especially if they come from underprivileged persons and groups. A fourth dimension has to do with the outcome of a group discussion. From a deliberative perspective, consensus is a good outcome, but it may be good enough if the actors acknowledge that the other side also has valid arguments. A fifth dimension asks whether all actors are free to speak up or whether they are constrained, especially by unwanted interruptions or other intimidations. The last dimension deals with the question whether actors actually mean what they say. This question of truthfulness is most difficult to get an empirical handle on. Crude lies are usually easy to detect, but otherwise the DQI limits itself to the question whether actors perceive each other as truthful.

Coding all speech acts of a discussion according to these dimensions gives a good overview of the deliberative quality of the discussion. Initially, we developed the DQI for parliamentary debates in Germany, Switzerland, the UK

3 For an overview of the place of the DQI in contemporary deliberative research see Simon Beste, "Contemporary Trends of Deliberative Research," Journal of Public Deliberation 9 (2013), issue 2.

4 The DQI is presented in the appendix of both books cited in footnote 1. 
and the US, both for plenary sessions and committee meetings. ${ }^{5}$ Speech acts in parliamentary debates have a high formality with the chair giving the floor to one actor after another. Thus, parliamentary speech acts have usually a certain length, which allows scholar to use the DQI to get at the dynamic aspects of a debate. André Bächtiger et al. have done this in a fruitful way for a Swiss parliamentary committee that discussed over eight sessions a language bill. ${ }^{6}$ They found, for example, that at first many actors told personal stories and that this storytelling greatly diminished over time. A further finding was that references to the common good and rational justifications also decreased over time.

The research situation is very different when we investigate informal group discussions of ordinary citizens. This was the case for our study of discussions between ex-combatants of the extreme left and the extreme right in Colombia and of Serbs and Bosnjaks in Srebrenica in Bosnia-Herzegovina. ${ }^{7}$ At the beginning of the discussions, moderators indicated that the topic for discussion was to find ways for peace and then let the discussion go wherever it went. The consequence was an often quick interactive pattern with many shortcuts, a pattern very different from formalized parliamentary debates. Sometimes, it happened that a participant uttered only a single word. According to the DQI, the discourse quality of such a speech act would be extremely low. From the perspective of Deliberative Transformative Moments (DTM), however, it would all depend on the context in which such a word is uttered. Let us discuss an example, where the utterance of a single word led the discussion to continue at a high level of deliberation. The example stems from a group of Colombian ex-combatants. Arturo, an ex-guerrilla, uttered the single word rehabilitation. What was the context in which this word was uttered? Before Arturo made this extremely short intervention, the discussion flowed at a high level of deliberation. The group addressed the issue whether the constitution should be amended allowing the death penalty for rapists. In a very interactive way, the group discussed this issue, addressing also alternatives like castration and life in prison. Arguments were justified, and participants showed respect for the arguments of others. Immediately before Arturo uttered the word rehabilitation, Bernardo, an ex-paramilitary, made the following statement:

Family is the nucleus of society. I see Colombia as a big family, and if I make a mistake and my brother goes to my father and tells him to beat me up, then we are not doing anything good. What we have to do is to provide the mechanisms and the means for that person to be able to realize the bad things he is doing and completely change his behaviour.

Bernard brings the alternative into the discussion that rapists should not be punished but should be helped to change their behaviour. To support his

5 Steiner et al., Deliberative Politics in Action.

6 André Bächtiger, Shawn Rosenberg, Seraina Pedrini, Mirjam Ryser, and Marco R. Steenbergen, "Discourse Quality Index 2: An Updated Measurement Instrument for Deliberative Processes," Paper Presented at the $5^{\text {th }}$ ECPR General Conference, Potsdam, September 10-12, 2009.

7 Steiner, The Foundations of Deliberative Democracy, pp. 15-21. 
argument, he claims that in a family it does not help when the father beats up a son, and he compares Colombia to a family. With this statement, Bernard keeps up the flow of the discussion, staying on topic and moving the discussion forward in adding another alternative, for which he gives a justification. Thus, the discussion stays at a high level of deliberation. What is Arturo attempting to accomplish when at this point he utters the word rehabilitation? Given the context, our interpretation is that Arturo gives Bernard a helping hand in telling the group that what Bernard suggests goes under the technical term of rehabilitation. With this helping hand, Arturo does not disrupt the flow of high deliberation. He clarifies for the group what Bernard suggests and, in this way, helps the discussion to continue on a more solid basis of knowledge. The discussion indeed continues to flow at a high level of deliberation. Coding the one-word speech act of Arturo with the DQI would give the impression that the level of deliberation had sharply dropped. According to our interpretation, however, uttering the word rehabilitation did not at all disrupt the flow of high deliberation but fitted well into its flow. With our approach, we look at how the individual speech acts are linked with each other.

The challenge in our research is to identify situations, where the discussion is transformed to a high level of deliberation or drops to a low level. How do we distinguish between the two levels? We take a qualitative approach, which has much to do with linguistics and social psychology. We look at what actors may wish to accomplish when they utter words in a particular context, and then we attempt to determine whether a transformative moment occurs. When a discussion drags on at a low level of deliberation, we look for mechanisms by which the discussion finds its way to a high level of deliberation. Thereby, it is not only important what speakers intend to say but also how listeners interpret what the speakers say. When, on the other hand, the discussion flows at a high level of deliberation, we look for mechanisms by which this flow is disrupted, and the discussion is transformed to a low level of deliberation. Given this research agenda, we have for each speech act four coding categories:

1) The speech act stays at a high level of deliberation.

2) The speech act transforms the level of deliberation from high to low

3) The speech act stays at a low level of deliberation

4) The speech act transforms the level of deliberation from low to high

The coding situation is not fundamentally different as for the DQI. In both cases, one makes a coding judgment for each speech act. For the DQI, one codes each speech act per se, for example, to what extent foul language is used or how well arguments are justified. ${ }^{8}$ For Deliberative Transformative Moments (DTM), we look at the entire context to determine which of the four coding categories applies. For both research projects, one has to make judgments that have to some extent a subjective nature. Therefore, it is not a question of quantitative versus qualitative research; in both cases one has to make qualitative judgments. For the DQI, one has much more coding data, since one codes several dimensions of the

8 Steiner et al, Deliberative Politics in Action. Steiner, The Foundations of Deliberative Democracy. 
discourse quality. Given the wealth of coding data, the usual publishing practice is that only the coding decisions are revealed but not their justification, or at most with some sample examples. The focus tends to be on complex statistical analyses showing the antecedents and consequences of variation in the DQI.

For the current project, we are not interested in statistical analyses. Our research strategy is rather to give a full description of how we arrived at our coding decisions. We tell in an in-depth way the story of each group discussion with its ups and downs. The reader is invited to follow closely how we interpret the dynamic that goes on in a discussion. Since our interpretations are fully revealed, the reader has the basis to take a different view on what is going on in a group. With this approach we are close to Ron Lubensky, who analysed the discussions of the Australian Citizens' Parliament (ACP). ${ }^{9}$ The title of his paper already indicates in what direction he wants to go with his analysis: „Listening Carefully to the Citizens' Parliament: A Narrative Account." He wishes „to open a window to the story of the ACP's participants." ${ }^{10}$ Lubensky does not claim that he has ,a master story from which all interpretations of the ACP should follow, nor (is he) claiming that the story line presented here is the only one." His main point is ",that a reflective, storied approach to analysing the events, based on narrative methods of discourse analysis, provides useful insight into the process and capacities of participants." This is pretty much what we have in mind in our current research.

In practical terms, we proceed in our coding in such a way that we try to put ourselves in the context in which each actor actually speaks. This means that we consider only the speech acts that are already uttered and not those that follow. Times and again, we went back to what was said before, checking the tapes and the transcripts making sure that we had a good feeling for the context in which an actor intervened in this discussion. Only when we had made a coding decision did we proceed to the next speech act. In this way, we try to follow the narrative of the discussion quasi life, which means as it is experienced by the participants themselves, who obviously do not know what will happen after they speak.

That one should not look at individual speech acts in isolation but in how they relate with what was said before is also emphasized by conversation theory, which is prominent among anthropologists. We became only recently aware of this theory and find it comforting to get support for our approach from outside the deliberative literature. In a review paper, Charles Goodwin and John Heritage put the core of conversation theory in these terms: „conversational participants will inevitably display some analysis of one another's actions. Within this framework of reciprocal conduct, action and interpretation are inextricably intertwined ... in the real world of interaction sentences are never treated as isolated, self-contained artefacts." ${ }^{11}$ Conversational captures well what is also our intention to analyse discussions as an interactive process.

9 Ron Lubensky, "Listening Carefully To The Citizens' Parliament: A Narrative Account," in Carson L, Gastil J., Hartz-Karp J, Lubensky R., (eds.), The Australian Citizens' Parliament and the Future of Deliberative Democracy, University Park. PA: Pennsylvania State University Press, 2013.

10 This and the following quotes Lubensky, "Listening Carefully," p. 66.

11 Charles Goodwin and John Heritage, "Conversation Analysis", Annual Review of Anthropology, Vol. 19 (1990), pp. 287-8. 
Although we do not look for authoritative stories, we are still interested how much reliability we get in our own coding judgments. We checked it for a randomly selected group of Colombian ex-combatants, where 107 speech acts were uttered. Each speech act was coded independently by Maria Clara Jaramillo and Jürg Steiner. The former is from Colombia, the latter from Switzerland. It is important that there is someone who is familiar with the local Colombian culture; but it is equally important to have someone who can look into the Colombian culture from a different cultural background. Given these different perspectives, it is comforting that reliability was high with an agreement between the two coders in 98 of the 107 speech acts. We acknowledge, of course, that the two of us have worked for many years together, so that it has to be expected that we tell the story of this discussion group in a similar way. Despite this caveat, the high reliability may still increase the trustworthiness of our results, at least for ourselves, and perhaps also for the readers.

How do we put our four coding categories in operational terms? Basically, for the discussion to flow at a high level of deliberation it must be somehow linked to the peace process, the topic assigned to the groups both in Colombia and Bosnia-Herzegovina. By contrast, the discussion is at a low level of deliberation if it drags on off topic without any clear direction. Deliberative Transformative Moments (DTM's) occur when the discussion changes from one level to the other. Specifically, we use the following criteria for our coding decisions:

\section{Code 1: The speech act stays at a high level of deliberation}

The coding is easiest if a speech acts fulfils all the criteria of the DQI mentioned above, which means that the speaker has not interrupted other speakers, justifies arguments in a rational way or with relevant stories, refers to the public good, respects the arguments of others and is willing to yield to the force of the better argument. The discussion, however, can still continue at a high level of deliberation if speakers do not fulfil all these criteria as long as they stay in an interactive way on topic. If a speaker, for example, simply supports the argument of a previous speaker without adding anything more, the discussion continues to flow at a high level of deliberation. An extreme example is the one word intervention of Arturo mentioned above. For our coding decisions the concept of topic has particular importance, by which we mean a subject matter that has a certain internal consistency. An example of a topic that we encountered in the discussions of Colombian ex-combatants is poverty in the country. As long as a speech act stays within this topic, even if the speech act is very brief and not very elaborate, the level of deliberation remains high. Our criterion is whether the discussion continues to flow in an interactive way on a particular topic with the actors listening to each other with respect. Deliberation also stays high if an actor introduces another topic and presents it in such a way that the other actors can understand it, especially in giving reasons why the topic is linked with the peace process. An actor may, for example, turn the discussion from poverty to corruption, a case that actually occurred in one of the groups of Colombian ex-combatants. 
If the issue of corruption is sufficiently linked to the peace process the discussion continues at a high level of deliberation.

\section{Code 2: The speech act transforms the level of deliberation from high to low}

We use this second coding category when the flow of the discussion is disrupted. The topic debated so far is no longer pursued, and no new topic related to the peace process is put on the agenda. Topics and stories may be mentioned that have nothing to do with the peace process and are therefore completely off topic. It is also possible that the speech act is so incoherent and confusing that it does not make sense. Under these various circumstances, there is no open space where other actors could easily continue the discussion in a directed way.

\section{Code 3: The speech act stays at a low level of deliberation}

We use the third coding category for speech acts that do not manage to give to the discussion again a direction linked with the peace process. The speaker is unable or unwilling to put on the agenda a topic relevant for the peace process. Instead, the speaker brings up topics or stories that are off topic, or the speech act is altogether incoherent and confusing. The key criterion for this third coding category is that the speech does not open windows for the group to talk about the peace process.

\section{Code 4: The speech act transforms the level of deliberation from low} to high

Speech acts coded according to this fourth category are successful in formulating a new topic relevant for the peace process. Success means that good arguments are presented why the topic should be discussed in connection with the peace process. In this way, the speech acts opens new space for the discussion to continue in a directed way.

Having established what we mean by Deliberative Transformative Moments (DTM), the further research task will be to investigate what happens after such moments. If they go upwards, we want to see how efficient they are, by which we mean how long afterwards the discussion continues to flow at a high deliberative level. For downward Deliberative Transformative Moments (DTM), we will check how detrimental they are, by which we mean how long afterwards the discussion drags on at a low level of deliberation. A further research task will be to explain the strong variation in the frequency of Deliberative Transformative Moments (DTM) among the various groups that we study.

At the beginning of the paper, we claim that the concept of deliberative transformative moment is new in the deliberative literature. We acknowledge, however, that Simon Niemeyer comes close to the concept, when in his $\mathrm{PhD}$ dissertation he writes about "turning points" in deliberation. ${ }^{12}$ We also note that Lyn Carson reports that a participant in the discussions of the Australian

12 Simon Niemeyer, Deliberative Monetary Valuation as a Political Economic Methodology: Exploring the Prospect for Value Pluralism with a Case Study on Australian Climate Change Policy, PhD dissertation, Australian National University, 2011. 
Citizens' Parliament actually talks about a „transformative” incident, when something unusually had happened changing the tone of the deliberations. ${ }^{13}$ Thus, it is not quite unknown in der deliberative literature that something like deliberative transformative moments exist, although the concept has not yet been fully developed. Outside the deliberative literature, the concept of catharsis has some similarities with our concept of transformative moments. It was initially presented by Aristotle in his response to Plato's critics on drama. According to Plato, drama should be closely controlled or eliminated, as it fosters human passions. Aristotle, on the contrary, argued that „dramatic catharsis was necessary, that it purged the audience of pity and terror ${ }^{14}$ " In fact, in his Poetics, Aristotle argues that „drama tends to purify the spectators by artistically exciting certain emotions, which act as a kind of homeopathic relief from their own selfish passions. ${ }^{15}$ " To be relieved from selfish passions fits well the situations when a discussion is transformed to a higher level of deliberation.

The concept of catharsis was also used in the early development of psychiatry. At the group level, Jacob L. Moreno explains how it was applied in the work on psychodrama that began in Vienna in the 1920's. „This change has been exemplified by the movement away from the written (conserved) drama and toward the spontaneous (psycho) drama with the emphasis shifting from the spectators to the actors." 16 Moreno's work is based on group dynamics and is indeed closely related to the idea of transformative moment. In fact, through a process of catharsis a change is produced in the actors in the psychodrama very similar to our concept of transformative moment. At the individual level, Thomas Scheff and Don D. Bushnell describe how Sigmund Freud in his studies of hysteria presented catharsis as a „quick, cheap and effective cure for hysterical neurosis." ${ }^{17}$ Scheff and Bushnell propose a theory of catharsis that involves three interacting systems, one biological, one psychological and one social. From the perspective of our own research, it is interesting to see how the concept of catharsis has a dynamic aspect similar to our concept of transformative moment.

Turning to contemporary research, the concept of transformation is particularly prominent in conflict and peace studies. John Paul Lederach uses the term conflict transformation, by which he means that a conflict is , a potential catalyst for growth." 18 Johan Galtung also speaks of conflict transformation; for him "to transform a conflict is to transplant it into a new reality" ${ }^{19}$ Conflict transformation is present when, accepting that conflict is both a source of

13 Lyn Carson, "Investigation of (and Introspection on) Organizer Bias," in Carson L, Gastil J., Hartz-Karp J, Lubensky R., (eds.), The Australian Citizens' Parliament and the Future of Deliberative Democracy, University Park. PA: Pennsylvania State University Press, 2013.

14 Thomas J. Scheff and Don D. Bushnell, "A Theory of Catharsis," Journal of Research in Personality 18 (1984), 238

15 Jacob L. Moreno, "Mental Catharsis and the Psychodrama," Sociometry 3, 3 (1940), 209.

16 Jacob L. Moreno, "Mental Catharsis and the Psychodrama," Sociometry 3, 3 (1940), 209.

17 Thomas J. Scheff and Don D. Bushnell, "A Theory of Catharsis," Journal of Research in Personality 18 (1984), 238.

18 John P. Lederach. The Little Book of Conflict Transformation. Good Books (2003). p.15

19 Johan Galtung. Conflict Transformation By Peaceful Means: A Trainer's Manual. United Nations (2000). p. 4 
creation and a source of destruction, we decide to act in such a way that the creative aspects take control. The task of transforming a conflict requires „finding positive goals for all parties, imaginative ways of combining them, and all of this without violence." 20

In education, Jack Mezirow understands transformative learning as "the process of effecting change in a frame of reference." ${ }^{21}$ Frames of reference, in turn, are the structures of assumptions through which we understand our experiences." 22 Finally, the United Nations Educational, Scientific and Cultural Organization - UNESCO - uses the concept of social transformation to describe a critical stance towards traditional notions of development. It „considers social transformation research as a field of research that can lead to positive steps for social and political action to protect local and national communities against negative consequences of global change." 23

These references to the scholarly literature at large indicate that the concept of transformation has a prominent place in many fields. Thereby, it is important to note that transformation is not simply a synonym for change but denotes a particular sort of change, namely an abrupt change in the sense of a catharsis. It is such transformations that form the topic of our new research. To present such research will be for another place. In this paper we only wished to introduce Deliberative Transformative Moments (DTM) as a new concept, of which we hope that it will be fruitful to get at the dynamic aspects of deliberation.

20 Johan Galtung. Conflict Transformation By Peaceful Means: A Trainer's Manual. United Nations (2000). p. 3

21 Jack Mezirow. "Transformative Learning: Theory to Practice." New Directions in Adult and Continuing Education 74 (1997) p.5

22 Jack Mezirow. "Transformative Learning: Theory to Practice." New Directions in Adult and Continuing Education 74 (1997) p.5

23 UNESCO. United Nations Educational, Scientific and Cultural Organization. Social Transformation. [online] Retrieved from: http://www.unesco.org/new/en/social-and-humansciences/themes/international-migration/glossary/social-transformation/ 